\title{
MULTIDISCIPLINARY DESIGN AND MODERN MANUFACTURING AS DRIVING FORCES FOR INDUSTRIAL ENGINEERS OF A FUTURE
}

\author{
JOVANOVIC, V.
}

\begin{abstract}
Nowadays, product design and manufacturing is no longer being done exclusively at one location. Moreover, engineering teams form based on a given task, a project or a current necessity. All of these reasons are influencing modern industrial organizations to become changeable and adaptable as never before. Information era and development of new computer technologies has changed the ways that work is done today in so many different aspects. Modern industrial engineer can work with people, who might be on different countries, and even different continents, collaborate with engineers with different backgrounds. In this global and multidisciplinary environment, there is a need for a new skillet, many of which are not hard engineering, number crunching kind of activities. Moreover, they are related to so called soft skills which are related to interpersonal, time management and adaptability to change and function in ever changing, fast passed business environment. Globalization has set a new stage for engineering operations around the world. Hence, industrial engineers are managing and planning operations which are interconnected to operations and manufacturing of goods and services which are not necessarily at the same location or the same company. Way how to manage huge amounts of information related these complex mechatronic systems and knowing how to retrieve the current and needed information is another skill which industrial engineer of future has to develop. This chapter will provide an overview of the current research areas related to aforementioned topics.
\end{abstract}

Key words: multidisciplinary design, modern manufacturing, product lifecycle management, mechatronic systems, environmental requirements
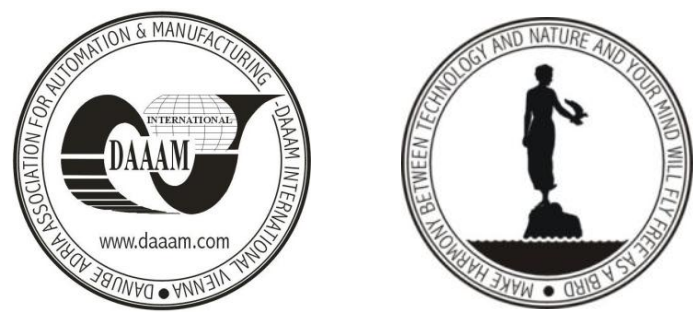

Authors' data: PhD Assistant Professor Jovanovic, V[ukica], 1 Old Dominion University, Mechanical Engineering Technology, 111-D Kaufman Hall, Norfolk, VA 23529,v2jovano@odu.edu

This Publication has to be referred as: Jovanovic, V[ukica] (2013) Multidisciplinary Design and Modern Manufacturing as Driving Forces for Industrial Engineers of a Future, Chapter 60 in DAAAM International Scientific Book 2013, pp. 969-984, B. Katalinic \& Z. Tekic (Eds.), Published by DAAAM International, ISBN 978-3-901509-94-0, ISSN 1726-9687, Vienna, Austria

DOI: $10.2507 /$ daaam.scibook.2013.60 


\section{Introduction}

Similar as all other engineers, an industrial engineer is on a mission to improve the world (Ravesteijn, De Graaff, \& Kroesen, 2006). They provide a necessary link between science and industry (Noble, 1999). Basically a job of every industrial engineer heavily relies on "finding new ways how to eliminate wastefulness in production processes, to try to optimize "the system" (Templin, 2013). They devise efficient ways to use workers, machines, materials, information, and energy to make a product or provide a service" $(\mathrm{OOH}, 2013)$. Another definition is that "Industrial Engineers design, improve, and install integrated systems of people, materials, information, equipment, and energy" (Koelling, Beruvides, \& Tankoonsombut, 1996; Mummolo, 2007). At the same time, industrial engineer has to provide the desired level of the output but also to match desired levels of economic planning (Knowles, 1952). Hence, a continuous quest for better, faster and more efficient methods is a quest of any industrial engineer (Wilson, 2013). These processes are known as industrial optimization. In essence, to be able to optimize production processes, industrial engineer of today has to know in depth many different aspects of different flow of material, information and energy in processes, and to understand how to manage people and use resources the best way possible in any kind of production environment. In today manufacturing world, this means that he or she would need to manage people and resources which are not at the same company site. This new working environment puts a pressure on work environment from entirely different perspective. Managing operations takes into account so many different aspects. Decision making process is so much different than what it used to be in the past while companies were able to manufacture and assembly products mostly on one location. There are many unknown parameters which might come into equation when it comes to decision that industrial engineers will need to face on a daily basis.

Industrial engineers started to merge in 1890s with the first time study methods developed by Frederick W. Taylor and Henry Gantt who developed work time scheduling charts for management of workers in the factory (Black, 2010). Carl Barth developed methods to calculate speed and feeds of machines, Frank Gilbreth invented methods for motion study and micro motion analysis which set the base for ergonomic improvements in production systems. Another studies started to emerge focused on worker motivation by Lilian Gilbreth. In essence, pioneers of industrial engineering profession were focused on development of new methods related to the idea of one best way to do a job (Black, 2010). Industrial engineers contributed in a great extent to the increased standard of living in industrialized countries (Holt, 1977). Another big challenge related to the profession came with the introduction of mass production in automotive industry by Henry Ford and Charles E. Sorensen. Mass production has led to multiple departments in factories and to a growth of industrial engineering profession in general. Nevertheless, recent trends related to manufacturing in developed countries have caused many layoffs in manufacturing positions and transferring operations to lower waged countries. However, a manufacturing sector still provides a significant share of employment even in highly developed countries (Mummolo, 2007). Therefore, industrial engineering is offered at many universities and provides many challenging and evolving careers in many different industry sectors. 


\section{Product Design and Realization in a Global Environment}

Companies from developed countries are focusing on research and development while repositioning their manufacturing operations outside their borders. Usually, this phenomenon is related to relocation of manufacturing operations to once underdeveloped countries such as India, China, Mexico and others. At the beginning this great idea of merging international markets has resulted in many different developments over the years. Some of them are very positive, such as higher number of jobs in countries who have got these new manufacturing facilities opened higher rates of export and lower prices at original location of the company. However, there were and still are many different issues related to this. Some are related to decreased number of manufacturing jobs in the developed countries, more complicated management of facilities which are located around the Globe. In a way, industrial engineer might sometimes be referred as a modern nomad who might be "working around the clock" while collaborating with engineers and workers from different time zones. Many of these engineers will learn how to work in a "market-driven" engineering environment and operate in a "knowledge society" (Koelling et al., 1996). They will become lifelong learners with the ongoing need to stay current in their specific area of expertise. In majority of instances industrial engineering programs in Europe are oriented more towards design and creative factors, and less on operational factors (Mummolo, 2007). They are not always current with the needs of industry which need engineers highly skilled in operations management and manufacturing optimization methods. Many companies have moderately low demand for innovation and a research workforce. Since majority of industrial sector in European Union are small and medium-sized enterprises (SMEs) are large percent of business (22.4\% in E.U.) comparing to $14.1 \%$ in the US and $7 \%$ in Japan (Mummolo, 2007). For these manufacturers who might need different emphasis in education of their industrial engineers, operations and manufacturing management plays more important role than innovation and design on new innovative manufacturing methods or systems. One of the crucial issues became how to attract creative people into industrial engineering major. Some of the tools used by industrial engineers on a daily basis are: work measurement, statistical process control, kanban, ANOVA, design of experiments, Taguchi arrays, robust design, fishbone diagrams, neural networks, lean Six Sigma, agile, simulation and linear optimization are all about creating a system to describe the world around us (Templin, 2013). Hence, industrial engineers have to be well versed in all these different manufacturing optimization methods. The notion of optimization as "there is always a better way" (Willemze, 1982 ) is not going to change in the near future. New innovative engineering methods are yet to be developed.

\subsection{Current Industry Trends and Needs for Industrial Engineers}

Some of the current trends in industry are related to high percentage of patents in the sectors such as: bio-nano technology, new materials, digital factories and plant miniaturization as well as in health, safety, and security of work environments and infrastructures (Mummolo, 2007), as shown in Table 1. 
Jovanovic, V.: Multidisciplinary Design and Modern Manufacturing as Driving For...

\begin{tabular}{|cccccc|}
\hline Company & $\begin{array}{c}\text { Technology Review } \\
\left.\text { innovation Index } \boldsymbol{*}^{*}\right)\end{array}$ & $\begin{array}{c}\text { R\&D 2003 } \\
{[\text { Million } \mathbf{~}]}\end{array}$ & $\begin{array}{c}\text { Variation in } \\
\mathbf{R \& D}(\boldsymbol{\%})\end{array}$ & $\begin{array}{c}\text { Variation in } \\
\text { R\&D [million } \\
\mathbf{\$}]\end{array}$ & $\begin{array}{c}\text { (R\&D/ Sales) } \\
(\boldsymbol{\%})\end{array}$ \\
\hline Pfizer & 178 & 7131 & 38 & 1955 & 16 \\
Amgen & 149 & 1655 & 48 & 539 & 20 \\
Nokia & 146 & 4514 & 23 & 850 & 13 \\
Johnson\& Johnson & 141 & 4684 & 18 & 727 & 11 \\
BMC software & 138 & 586 & 20 & 96 & 41 \\
Volkswagen & 138 & 4233 & 22 & 762 & 4 \\
Sony & 136 & 4683 & 16 & 649 & 7 \\
Merck (US) & 135 & 3178 & 19 & 501 & 14 \\
Serono & 134 & 468 & 31 & 110 & 25 \\
AstraZeneca & 134 & 3451 & 12 & 382 & 18 \\
Microsoft & 133 & 4659 & 8 & 352 & 14 \\
Roche & 133 & 3694 & 12 & 396 & 15 \\
Novartis & 133 & 3756 & 12 & 394 & 15 \\
Intel & 132 & 4360 & 8 & 326 & 14 \\
Nissan Motor & 129 & 3225 & 18 & 491 & 5 \\
\hline
\end{tabular}

${ }^{(*)}$ The innovation index is based on R\&D expenditures, percentage and absolute variations, and on \% of R\&D on Sales. Tab. 1. A patent map according to the technology review innovation index (Mummolo, 2007)

\subsubsection{Nanotechnology and biomedical engineering}

Nanotechnology as an art of manipulating materials on an atomic or molecular scale to build microscopic devices in $1-100 \mathrm{~nm}$ range has provided new challenges to manufacturing and industrial engineers (Ahmed \& Jackson, 2009; Drexler, 2013).

One of the key focuses nowadays is how to make "nano" products marketviable. It is estimated that about 2 million workers will be needed worldwide in the next decade (Mummolo, 2007). One of the key innovations for nanotechnology would be related to application of design of experiments methods, environmental and occupational health safety issues which are related to nanostructures and their fabrication. High accuracy engineering, metrology and manufacturing need high precision machines, instruments and components (Mamilla \& Sekhar, 2010).

Some of the new ideas are that nanotechnology might change the nature of the health care and move the "see and treat" world to "predict and prevent" world and develop technologies which might even destroy cancerous cells in human body (Ghadar \& Spindler, 2005). Some of the manufacturing applications of nanotechnology are frictionless machine bearings that will never wear, nano machines which might extract energy from their surroundings etc. Some of the areas of nanotechnology are related to new superconducting cables and more energy efficient light emitting diodes (LEDs).

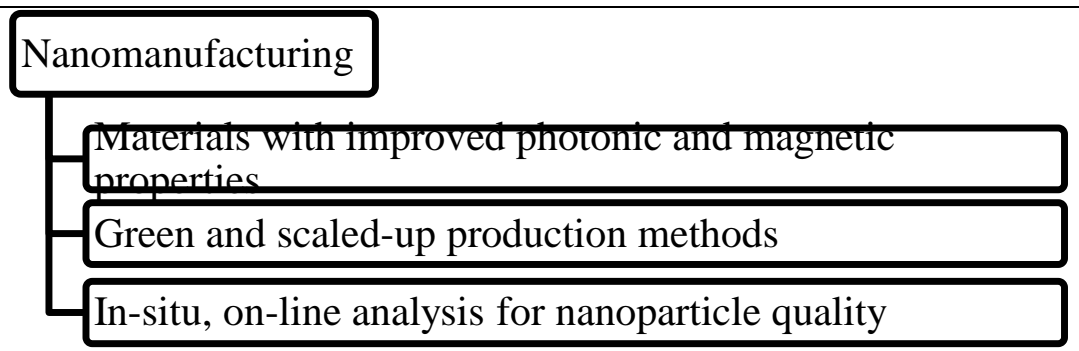

Fig. 1. Schematic of programs within nanomanufacturing (Wong et al., 2007) 
Other ones are related to research related to new kinds of materials such as resilient nanocomposites and carbon nanotubes (Ghadar \& Spindler, 2005). In addition, products such as sports equipment, wrinkle and stain resistant fabrics, high capacity batteries, UV resistant cosmetics, flexible electronic displays and high efficiency solar panels are some of the products which are being manufactured by nano manufacturing industry (Conard, 2013). The key is to develop higher performance products which would be stronger, lighter, more efficient, safer with low emissions and greater computational power (Drexler, 2013). Concurrently, some industrial engineers work as a part of multidisciplinary teams such as ones related to biomedical research. One of these research projects is related to tissue engineering and organ printing, in which engineers are using rapid prototyping technology to print organs from patient's own cells (Tarik Ozbolat, 2013), as shown in Figure 2.

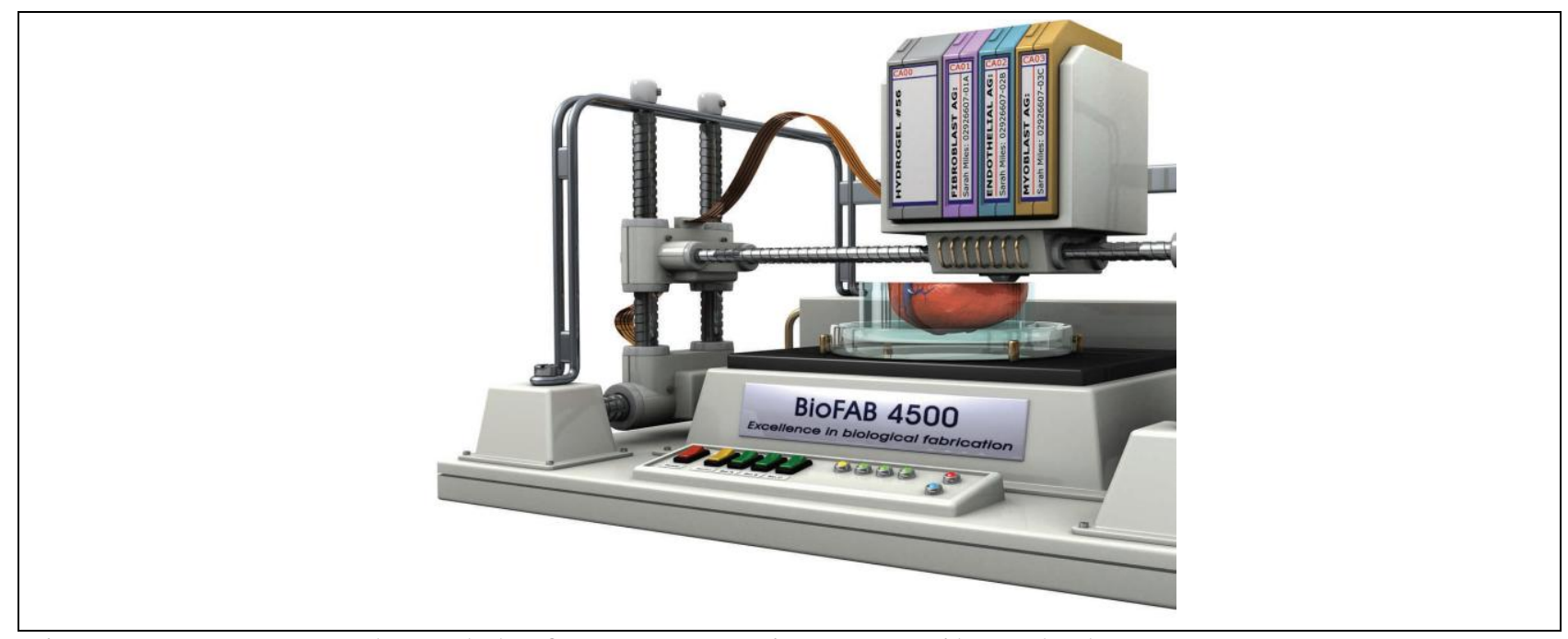

Fig. 2. A conceptual model of an organ printer (Tarik Ozbolat, 2013)

\subsubsection{Smart materials}

Smart materials respond rapidly to external stimuli to alter their physical properties (Singh, 2005). They include self-healing materials, smart sensing materials, sensing skins, and shape-changing materials which can be used in the aerospace, defense, automotive, civil engineering, medical, robotics and other industries (Bogue, 2012). Consequently, another group of smart materials, biopolymers, and electronic equipped textile materials are examples of new materials that are more environmentally compliant or capable of modifying their performance in a changing environment (Mummolo, 2007). One example of such material is textile material having different thermo-physiological properties according to environmental temperature. Other examples are nanomaterials for energy harnessing and storage, photovoltaic materials and devices, biomaterials and tissue engineering etc. (Zhong, 2012). Another are related to intelligent packaging which would be package containing additional component into the package content or its material in order to maintain or improve product quality (Jazukevičiūtè, Kibirkštis, \& Miliūnas, 2013), as biosensors embedded in food packaging which would recognize pathogens in food packaging. Many researchers are currently investing fabrication methods how to use materials which are developed with the main idea to mimic the things learned from the nature. The nature has been one of the main inspiration for scientists and 
engineers who are developing new bio-inspired smart materials (Kesong, Ye, \& Lei). Modern inventions which can be build based on the things observed from nature include products such as: spy drones, raindrop power generators, camouflage clothing, morph aircrafts, jellyfish robots, Compact hybrid electrohydraulic actuators, along with the smart materials embedded in smart snow-skis which absorb the vibrations on skier's feet (Chaudhuri \& Wereley, 2012; Pool, 2012). Another industry application of piezoelectric smart materials is in automotive industry for improvement of damping methods, and therefore vehicle performance and operator ergonomics (Ivers \& LeRoy, 2013). In addition, smart materials can be used for manufacturing devices for active product disassembly (Chiodo \& Jones, 2012). Hence, new studies of plant miniaturization and nanotechnologies will be of increasing importance both in research and in industry. Miniaturization is expected to provide low cost plant as well as environmentally compliant industrial processes. The benefits are mainly expected in health and safety concerns of hazardous industries (chemicals, petro-chemicals, pharmaceuticals, steel, nuclear, etc.).

\subsection{Information Era and Global Engineering Operations}

In addition, more manufacturing companies do not have research and development departments on site. They have research development in the corporation or even more they might hire an engineering consulting firm to provide design and development for their products. Additionally, they might subcontract manufacturing and assembly of many sub-assemblies and assemblies or even whole products in their product line. Managing data about discontinued products, providing customers with maintenance and service operations is also another area in which are companies moving towards the digital world. They are developing legacy systems in which they store information about products which are no longer being manufactured. Another very important change is related to customers themselves. In this information area, it is easy to obtain information about products. Customers can get reviews from other customers who already used products and get more insight related to product quality and customers' experience even before purchase. Hence, aiming for the maximum quality possible has become one of the main goals of any company. Some of the strengths of industrial engineering are in logistic and distribution (Martin-Vega, 2008).

To operate efficiently as a part of a bigger manufacturing company, one also has to understand subtle cultural and operational differences among different countries and way the companies operate their businesses. One example is related to roles and responsibilities of manufacturing engineers in Japan and U.S. Japanese firms might structure their manufacturing operations in horizontal division of labor between manufacturing design engineers and production process engineers, in contrast to a vertical division of labor between manufacturing engineers and technicians in three American firms (Shibata, 2009). In addition, involvement in decision making processes might differ from country to country. Some companies will have more hierarchical and structural decision making processes some will have other approach with dealing with changes.

One of the problems which need additional attention in future is that control system networks in industry are especially vulnerable to certain kinds of attacks (Ginter, 2013). Security of production systems and infrastructure will also be 
considered with traditional safety problems and the need for new design and operational guidelines will become noticeable. The scientific and industrial interest in the concept of plant vulnerability will increase; design and operation guidelines will be more and more safety and security oriented (NPRA Guidelines 2004).. Hence, additional research has to be directed towards making these systems safer and less open to potential cyber-attacks.

\subsubsection{Collaborative Nature of Manufacturing}

Collaboration is the sharing of ideas, opinions, and perspectives between knowledgeable people with differing backgrounds. One of the principles of organizational learning is to incorporate a variety of perspectives in any work performed. These perspectives can be across work groups, specialties, functions, and even external to the organization. Internal perspectives might be the upstream and downstream processes from your own, business improvement and management consultants, and individuals and functions with knowledge or expertise in the domains of interest. External perspectives might include customers and stakeholders, regulatory agencies, and academia/industry special interest groups in the areas of expertise (Liebowitz, 1999).

The "communicative competence" is one of the main assets of engineers who are involved in activities related to innovation, together with the discipline related technical and scientific knowledge (Mummolo, 2007). Engineers who have high competence in communication are today social necessity and a link which will fill the gap between invention and innovation (Ravesteijn et al., 2006). Innovation is not enough itself; there is a need to manufacture innovative products with desired cost and quality at the right time. It has never been easy to get from invention to innovation, from an excellent idea to successful implementation (Ravesteijn et al., 2006). Communicational competence related to capabilities of a person dependent upon (tacit) knowledge and (ability for) use (Zascerinska, 2010).

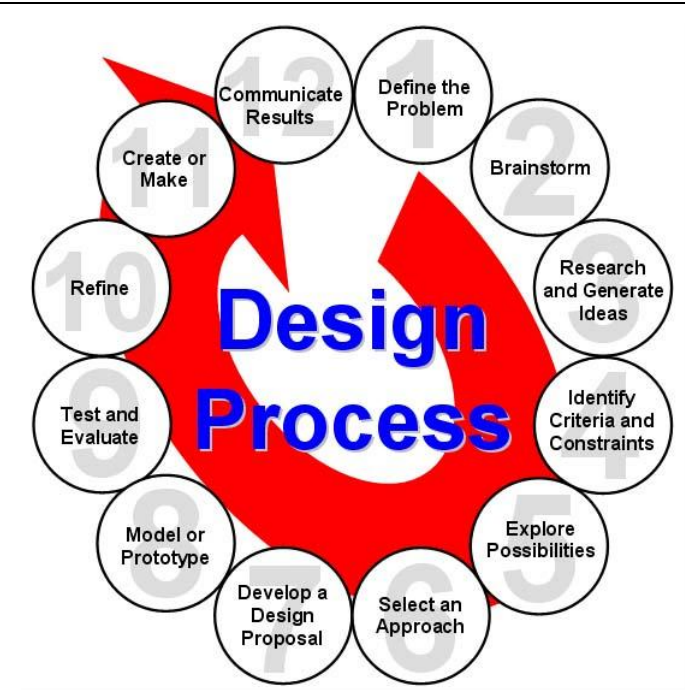

(a)

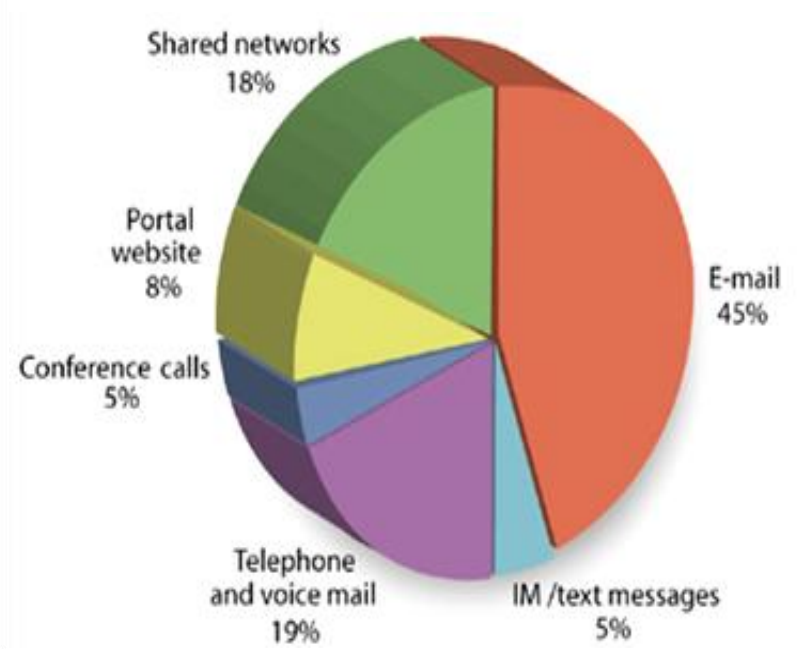

(b)

Fig. 3(a) ITEA Standards for Technological Literacy (b) Average percentage of information processing time spent on each medium, based on average hours spent (Davenport, 2006) 
International Technology Education Association (ITEA) identified the term "technological literacy". In order to be a technologically literate citizen, a person should understand what technology is, how it works, how it shapes society and in turn how society shapes it. Moreover, a technologically literate person has some abilities to "do" technology that enables them to use their inventiveness to design and build things and to solve practical problems that are technological in nature. A characteristic of a technologically literate person is that they are comfortable with and objective about the use of technology neither scared of it nor infatuated with it (ITEA, 2007). Standards for Technological literacy are shown in Figure 3. One of the required skills, according to this study, is know how to develop an understanding of and be able to select and use information and communication technologies.

Many industrial engineers are currently involved in things related to quality improvement and continuous improvement while still manufacturing products in given cost limitations with as little overhead as possible. They are designing manufacturing and assembly systems which are ergonomic and human friendly in order to achieve high efficiency and production rates. Since there are many computer aided software available to assist industrial engineers to use their manufacturing systems as efficient as possible. For this purpose, modern industrial engineering also includes knowledge of software and information technology in a great extent. Work in virtual teams includes many digital collaboration tools which are huge part of daily activities of many industrial engineers.

\subsubsection{Product lifecycle management (plm)}

Manufacturing industry has shifted from make-to-order, to build-to order, to engineering-to-order, to configure-to-order, to design-to-order, and in near future to innovate-to order (Gecevska, Anisic, \& Chiabert, 2011). In addition, manufacturing knowledge is now captured through different means of informational technology embedded in Product Lifecycle Management software tools which are supporting modern Computer Aided Engineering systems (Gunendran \& Young, 2010).

International and local outsourcing have changed the way that products are designed, manufactured and assembled. Their whole product lifecycle management has become more digitalized. Data about parts, operations, facilities, tools, workers and all information related to product design and manufacture are stored on manufacturing informational hubs, or backbones. The need for the current, up-to-date information has become necessary. Even if the suppliers are in the same region or country, there is extensive data management involved in almost any coordination activity related to a job of industrial engineer. Planning and resource allocation needs to be done internally in a company but is related to all influences related to external elements for all companies involved in different phases of the product lifecycle.

Many companies still have departments who are still function "in silos", which mean that they do not communicate information successfully horizontally (Engle, 2013). Information flows only vertically, from the supervisor to employee and vice versa. The problem with this approach is that different departments do not share important data about product development, manufacturing, assembly, and all different stages of the product lifecycle. For this reason, changes are no implemented successfully and on time. Data about the products is not always current, and different departments are not up to date to all the changes which are ongoing in the company. 
With large PLM applications, any configuration change in the collaborative product development has to be made at the server level by dedicated staff in large companies. There is one problem that arises when enterprises wish to collaborate with a large number of suppliers and original equipment manufacturer (OEM) customers. Collaborative tools can be Web-based collaborative tools and software collaborative tools if the method of their usage is considered. Divided by the area of their usage, they can be Knowledge management tools, Knowledge creation tools, Information sharing tools, and Collaborative project management tools. Most collaboration systems and presentation systems today are fundamentally systems for manipulating and sharing documents. Collaboration systems are developed around email and the web, both document interfaces with some stovepipe media capabilities glued on as afterthoughts through the mechanism of MIME (Multipurpose Internet Mail Extensions) attachments (Bajcsy et al., 2006). What people need is a shared workspace similar to physical meeting rooms in the real world. The shared workspace can provide an identical visual and operable working area among geographically separated participants. It is one of the most important features of synchronous collaboration systems (Saddik, Yang, \& Georganas, 2007). Any collaboration solution has to be extremely friendly and promote efficient communications between any two team members in distributed working environment. Access rights and security has to be achieved at all locations.

It is important to enable which user has the access to which data. By using a distributed architecture, any employee at company and at its partner companies can securely collaborate with one another. Usually engineers who are working in global teams can be classified as "knowledge workers". All knowledge workers spend a lot of time in meetings. They also process information and knowledge - on paper, in telephone conversations and voice messages, and electronically. Knowledge workers spend ever larger amounts of time messaging, creating documents, searching for information and knowledge, and other information-intensive activities. Desktop PCs, laptops, landline and cell phones, PDAs, handheld communicators, and other assorted technologies, paper-based tools, have been largely unconnected (Davenport, 2006), as shown in Figure $3 b$.

Individual knowledge work improvement initiatives have two attributes: improving performance of knowledge worker employees as individuals, not as members of a larger group and individually oriented initiatives are targeted at improving some skill or capability, rather than instituting a new process (Davenport, 2006). Communication overhead can add some hidden costs so the overall cost savings in those projects, held in a global environment could be really smaller than they appear in a company report. Audio and video conferencing, long distance calls and travelling are necessary of keeping track of all information related to the different phases in the project and product lifecycle. Some recent developments in communication technologies like Voice over Internet Protocol (VoIP) can lower the costs of international calls and can make the communication more affordable .

Product lifecycle is becoming shorter and changes that are occurring because of the frequent production program changes, are leading to the necessity of quicker data transfer among the engineers. An application of product lifecycle management software and digital manufacturing concept is enabling transfer of accurate, updated data. Digital manufacturing is a term that is related to wide spectrum of digital 
models and methods that are dealing with every aspect with product lifecycle management (PLM). It is basically integration among different tools used for product design (CAD, process planning (CAPP), time management and business applications, layout planning, ergonomics, simulations of robot work cells, process simulation, PLM systems, analysis software, CAM software and other applications used for planning and process optimization of a real company. Introducing data exchange through the Internet based applications for product lifecycle management in student project, new experts would be educated that would work in companies in distributed manufacturing systems (V. Jovanovic, Tomovic, \& Filipovic, 2008).

\subsubsection{Knowledge management and ergonomic analysis of production systems}

Modern engineering software applications have tools available for industrial engineers to develop their own data bases of previous configurations of production and assembly systems which can provide templates for easier and faster design of new systems. One example of such database which was built based on 3D models retrieved from various manufacturers and from various Computer Aided Design (CAD) software is given in Figure 5.

Digital models of equipment, tools and fixtures used in assembly systems might be built into the company's knowledge management repository and enable industrial engineers to deliver their solutions to reconfiguration in the layouts faster. This kind of database can include various levels of templates: modules used in assembly system, previous configurations that were successful, and database of digital manikins which would have ergonomic information about the workers in the manual assembly line. Ensuring that a workplace fits to a worker is becoming an increasingly important aspect of a design. Hence, an ergonomic analysis is very important task of any optimization process of a manual assembly system. The main reason for that is that fatigue of workers can lead to many different occupational hazards to human health. Working on repetitive tasks in a badly designed workstation can be very cumbersome for a worker and on the long term not cost effective for the company since after a while worker can be fatigued or develop some health problem. One example of an analysis for a human activity in an assembly system is RULA (rapid upper limb assessment) analysis, which is given in Figure 6.

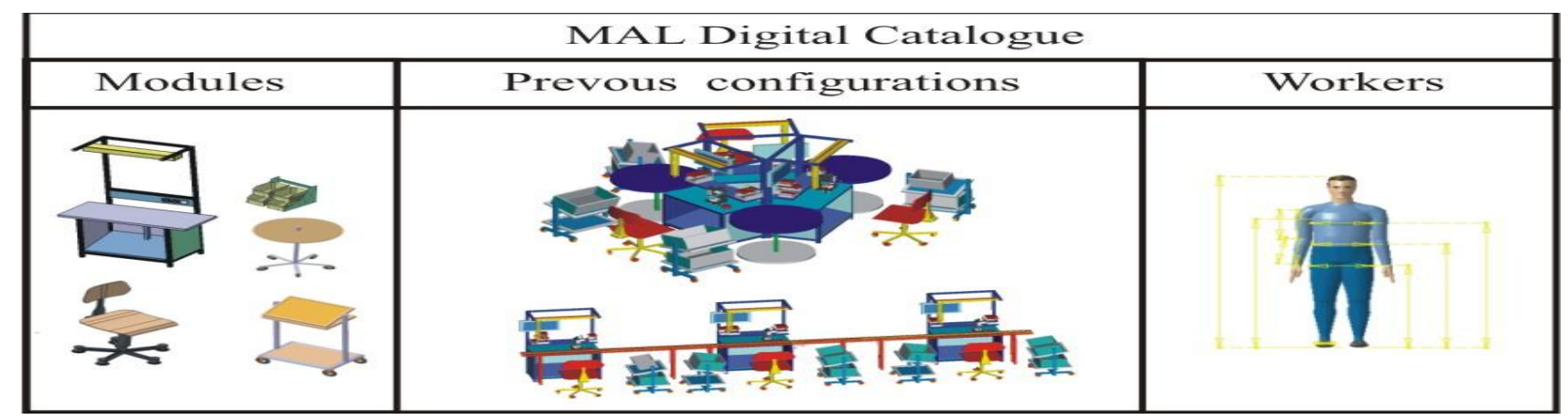

Fig.5. Digital catalogue structure (Jovanovic et al., 2007) 


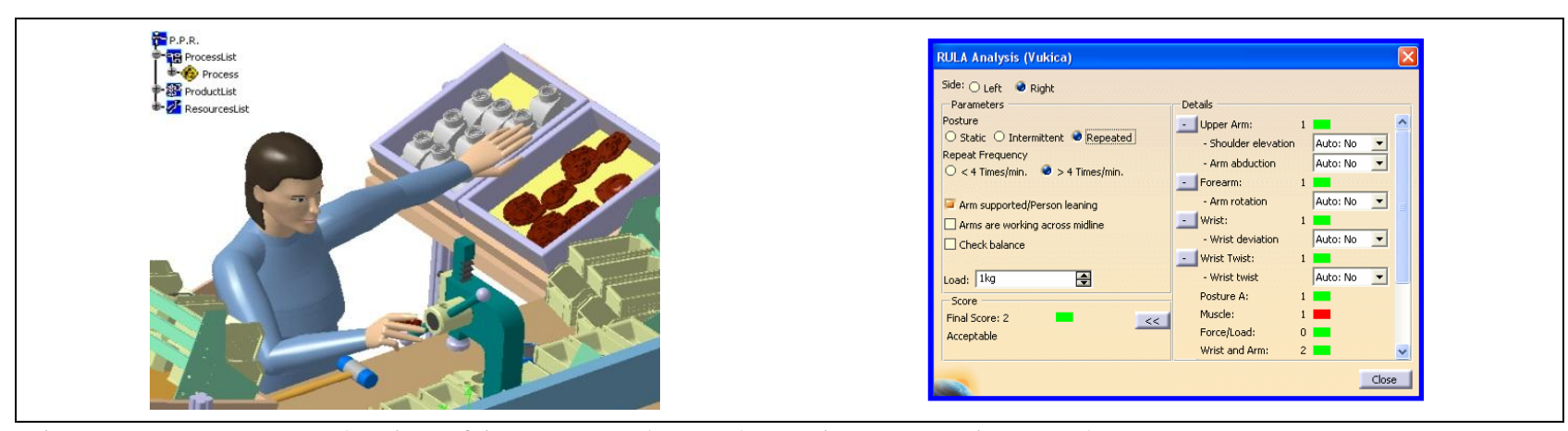

Fig. 6. RULA analysis of improved workstation (Cosic at al, 2008)

This tool provides a quick assessment of the postures of the neck, trunk and upper limbs along with muscle function and the external loads experienced by the body (Mc Atamney, 1993). It examines the following risk factors: number of movements, static muscle work, force, working posture and time worked without a break. All these factors combine to provide a final score that ranges from one limit to another.

One way to deal with this problem might be education engineers of the future to be open for cross departmental communication and up to date data sharing. These methods could be achieved through extensive use of informational technology through Product Data Management and Product Lifecycle Management. Another way is to form cross functional teams which would break inter departmental barriers. Concurrent or simultaneous engineering is one methodology to approach this issue (Engle, 2013). For this purpose, engineer of the future has to have extensive problem solving, team building, conflict resolution and other critical skills which are highly sought for easy and fruitful team management.

\section{Mechatronics and Multidisciplinary Design and Realization}

Mechatronics is a complex, highly technical and multidisciplinary field involving the design and manufacture of integrated products (Shyr, 2012). Design of new manufacturing workstations and operations needs collaboration among engineers from different backgrounds. Design and development of mechatronic products is very challenging (Torry-Smith et al., 2013). Systems engineering and mechatronics are areas of industrial engineering that has gained rapid development in recent years. Mechatronics is an integrated and integrating approach to the design, development and operation of complex systems (Bradley, 2013). It has changed recently due to significant developments in technology, and in particular in processing power and influenced new designs of wide range of products and systems from domestic appliances and consumer goods to manufacturing systems and vehicles. These products might be related to different industry fields such as aerospace, defense, automotive, transportation etc. Mechatronic systems require a concurrent design of mechanical, electrical, and information processing sub-systems in order to reach the cost requirements (Schöner, 2013).

Mechatronic design is the integrated design of a mechanical system and its embedded control system (van Amerongen, 2013). Many products which are being designed, manufactured and assembled today are multidisciplinary systems which are usually very complex products and multi-domain systems (de Silva \& Behbahani). A 
challenge to every design engineer is how to do effective systems and optimization of essentially multidisciplinary and complex mechatronic systems (da Silva \& Goncalves, 2013). To manage and determine their reliability, industrial engineers need to use advanced optimization techniques such as multi-state system (MSS) reliability, stochastic process methods, statistical analyses, fuzzy systems or heuristic algorithms (Lisnianski, Frenkel, \& Ding, 2010). They need concurrent and integrated methodologies and tools based on the latest theories such as bond graph theory or genetic programming (Behbahani \& De Silva, 2013).

Traditional binary reliability models which allow to possible states for the system, which focus either on a component's complete failure or perfect functionality (Dodson \& Nolan, 1999), are no longer sufficient to describe complex nature of many mechatronics and multi-state components which are basic part of many of modern products. Hence, industrial engineers who will design or manufacture mechatronic systems, will have to learn how to aims to integrate various stages such as design, simulation and physical implementations in development of mechatronics product or system (Yu et al., 2012). Many of these products have stringer and stringer environmental requirements. In addition, mechatronic devices such as auto-guided vehicles $(\mathrm{AGVs})$ are used inside greenhouses to manage plant production and to enable greener operations (Sánchez-Hermosilla et al., 2013). Autonomous robots, auto guided vehicles and aircrafts are constantly getting more interesting areas of application. New developments will be related to innovative methods of storing and creating energy since all these devices operate usually on electrical power.

\section{Environmental Requirements in a Global Setting}

Energy and environment topics will increase in importance in the spectrum of educational topics related to industrial engineers (Mummolo, 2007). Modern production systems have to be designed with emphasis on environmental and energy considerations as essential consideration. Negative environmental influences which are leading to depletion of natural resources, along with the persistent nature of world poverty and social problems around the globe are leading to new technology advances which would reverse this trend in the future (Ravesteijn et al., 2006). Higher level of energy independence worldwide is now acknowledged to be a result of the significant role played by industrial engineers in integrating renewable source technologies with safe and cost-effective means of supplying and distributing these technologies (Martin-Vega, 2008). Not only that saving energy is related to the main goal of every company which is to reduce production costs, it is also related to environmental regulations which are getting stringer and stringer each year. More importantly, companies are trying their best to serve as global citizens and form an environmentally friendly image on the market which will give them a competitive edge over their competitors. Various production management strategies have been introduced over the years and they have gain attention of many researches over the Globe. Some are related to Lean Manufacturing principles, Six Sigma methods, Green engineering, Design for Environment and Compliance methodologies. Companies are trying to focus on efficiency programs, product environmental compliance requirements while enabling full support for all suppliers and customers involved in the product lifecycle (Taisch, Cammarino, \& Cassina, 2011). Industrial 
engineers who will be in charge of these future changes will be armed with knowledge and ongoing desire to learn about all needed current lean analysis tools with which they can reduce waste in production systems with their "lean thinking mentality" (Black, 2010). Challenge which they will face throughout their daily activities will be how to create socially and environmentally acceptable products with as little waste as possible internally in the company and externally to the environment (as a company and through their product to their customers). When asked whether their companies are implementing lean operating principles, $56 \%$ of manufacturing executives answered yes in 2008, and 61\% answered yes in 2009 in the U.S. national online survey which included 920 executives of manufacturing and whole distributors (Black, 2010). This trend continues to grow each year.

Many companies have developed different strategies implementing green and lean principles into manufacturing systems design, operational improvement, and process control (Black, 2010). Based on this information, future research areas related to industrial engineering will be focused on finding new and improving new methodologies in areas related to waste reduction from company processes.

\begin{tabular}{|lcc|}
\hline \multicolumn{1}{c}{ Industry Segment } & Yes (2008) & Yes (2009) \\
\hline Industrial equipment & $61 \%$ & $65 \%$ \\
\hline Food and beverage & $45 \%$ & $52 \%$ \\
\hline Metal fabrication & $68 \%$ & $68 \%$ \\
\hline Transportation equipment & $42 \%$ & $70 \%$ \\
\hline Building materials & $51 \%$ & $55 \%$ \\
\hline Plastics & $65 \%$ & $64 \%$ \\
\hline Electronics & $61 \%$ & $67 \%$ \\
\hline Chemicals & $55 \%$ & $59 \%$ \\
\hline Printing, publishing & $55 \%$ & $51 \%$ \\
\hline Medical devices & $61 \%$ & $87 \%$ \\
\hline Total & $56 \%$ & $61 \%$ \\
\hline
\end{tabular}

Tab.2. Lean operating principles application in manufacturing and whole distributors (Black, 2010)

\section{Conclusion}

In the future, industrial engineering education will need to add more perspective to students to things which are not related only to the technical and instrumental competence but also on a communicative competence and project-based learning (Ravesteijn et al., 2006). Furthermore, various advanced optimization and mathematical modelling techniques will still be one of the main assets of modern industrial engineering. Industrial engineers of the future have to be able to understand the complex process and to understand the nature of constraints. In addition, they will have to decide which important noise factors are and which might be ignored for the sake of the simplicity of mathematical model, which is an ongoing battle of any optimization problem, especially if it is a multidisciplinary problem which many of the products which are being manufactured today essentially are. Moreover, an industrial engineer of the future will have to be a lifelong learner with ongoing will to 
adapt and to learn new approaches and new technologies since they are changing constantly with every new invention. Another very important challenge will be how to learn how to bridge the gap between invention and innovation. Adapting new ideas to feasible products and develop appropriate and cost effective manufacturing systems and processes will always be one of the main concerns of an industrial engineers. Many engineering areas are nowadays overlapping; teams are formed based on a current project, six sigma improvement project and any other given necessity. Therefore, ability to efficiently work as a part of multiple different teams which are finding solutions for diverse challenges which occur in their products and manufacturing systems is another great asset to have. Skills related to information literacy, global literacy, digital literacy and all different activities which any member of a virtual and face to face team need to use during different phases in team forming, development and performing phases. Hence, additional curriculum development efforts need to focus on development of soft skills which are needed for collaboration, to prepare industrial engineers to successfully adapt and find solutions to specific challenges in their future profession. They also need to master skills related to optimization and improvement of manufacturing processes and methods and to be well versed with decision making strategies. Current information, proper data analysis and successful knowledge management will be great assets of any industrial engineer.

\section{References}

Ahmed, Waqar, \& Jackson, Mark J. (2009). Emerging nanotechnologies for manufacturing [electronic resource] / edited by Waqar Ahmed and Mark J. Jackson: Oxford, U.K. ; Burlington, Mass. : William Andrew, 2009. 1st ed.

Bajcsy, R., Sang-Hack, Yung, Elenzil, O., Wilson, B., McGeer, R., Nahrstedts, K., \& Strothotte, C. (2006, 26-27 Jan. 2006). New Collaborative Tools. Paper presented at the Creating, Connecting and Collaborating through Computing, 2006. C5 '06. The Fourth International Conference on

Behbahani, S., \& de Silva, C. W. (2013). Mechatronic Design Evolution Using Bond Graphs and Hybrid Genetic Algorithm With Genetic Programming. Mechatronics, 18(1), 199

Black, j T. Phillips Don T. (2010). The lean to green evolution. Industrial Engineer: IE, 42(6), 46

Bogue, Robert. (2012). Smart materials: a review of recent developments. Assembly Automation, 32(1), 3-7. doi: 10.1108/01445151211198674

Bradley, D. (2013). Mechatronics - More questions than answers. Mechatronics, 20, 827841. doi: 10.1016/j.mechatronics.2010.07.011

Chaudhuri, A., \& Wereley, N. (2012). Compact hybrid electrohydraulic actuators using smart materials: A review. Journal of Intelligent Material Systems and Structures, 23(6), 634

Chiodo, Joseph, \& Jones, Nick. (2012). Smart materials use in active disassembly. Assembly Automation, 32(1), 8-24. doi: 10.1108/01445151211198683

Conard, Dennis. (2013). Nanotechnology: the future of New York state manufacturing. Business Journal (Central New York), 27(15), 27

Cosic, I., Jovanovic, V., \& Filipovic, S. (2008). An Enclosure to an Computer Aided Designing of Technological Assembly System. Paper presented at the XIV International Scientific Conference on Industrial Systems IS `08, Novi Sad, Serbia 
da Silva, M. M., \& Goncalves, L. A. M. (2013). Mechatronic design concept and its application to pick-and-place robotic systems. Sensors, 35(1), 40

Davenport, T. (2006). Thinking For a Living. How to Get Better Performance and Results from Knowledge Workers. Boston, MA: Harvard Business School Press

de Silva, C. W., \& Behbahani, S. . A design paradigm for mechatronic systems. Mechatronics. doi: 10.1016/j.mechatronics.2012.08.004

Dodson, Bryan, \& Nolan, Dennis. (1999). Reliability engineering handbook / Bryan Dodson, Dennis Nolan: New York : Marcel Dekker, 1999

Drexler, K. Eric. (2013). A Radical Future For nanotechnology. Futurist, 47(5), 14-20.

Engle, Paul. (2013). Silos are meant to be broken. Industrial Engineer: IE, 45(7), 18-18.

Gecevska, Valentina, Anisic, Zoran, \& Chiabert, Paolo. (2011). SOLUTIONS OF COLLABORATIVE PRODUCT LIFECYCLE MANAGEMENT. Acta Technica Corvininesis - Bulletin of Engineering, 4(3), 21-27

Ghadar, Fariborz, \& Spindler, Heather. (2005). Nanotechnology: Small Revolution. Industrial Management, 47(3), 13-20

Ginter, Andrew andrew ginter waterfall-security com. (2013). Securing Industrial Control Systems. (cover story). Chemical Engineering, 120(7), 30-35

Gunendran, A. G., \& Young, R. I. M. (2010). Methods for the capture of manufacture best practice in product lifecycle management. International Journal of Production Research, 48(20), 5885-5904. doi: 10.1080/00207540903104210

Holt, Knut. (1977). Creativity--a new challenge to the industrial engineer. International Journal of Production Research, 15(5), 411

Ivers, D., \& LeRoy, D. (2013). Improving vehicle performance and operator ergonomics: Commercial application of smart materials and systems. Journal of Intelligent Material Systems and Structures, 24(8), 907

Jazukevičiūtè, E., Kibirkštis, E., \& Miliūnas, V. (2013). Nanoparticles and Smart Materials Application in Packaging and Printing Technologies. Mechanika, 93-97.

Jovanovic, V., Tomovic, M. M., Cosic, I., Miller, C., Ostojic, G. (2007). Ergonomic Design of Manual Assembly Workplaces. Paper presented at the 2007 Annual American Society of Engineering Education IL/IN Section Conference, Indianapolis, Indiana, USA Jovanovic, V., Tomovic, M., \& Filipovic, S. (2008). An Introduction to Digital Manufacturing. Paper presented at the XIV International Scientific Conference on Industrial Systems IS `0, Novi Sad, Serbia

Kesong, Liu, Ye, Tian, \& Lei, Jiang. Bio-inspired superoleophobic and smart materials: Design, fabrication, and application. Progress in Materials Science. doi: 10.1016/j.pmatsci.2012.11.001

Knowles, William H. (1952). ECONOMICS OF INDUSTRIAL ENGINEERING. Industrial \& Labor Relations Review, 5(2), 209-220

Koelling, C. Patrick, Beruvides, Mario G., \& Tankoonsombut, Kriengkrai. (1996). Technology's impact on the future of industrial engineering. Computers \& Industrial Engineering, 31(1-2), 5-8. doi: http://dx.doi.org/10.1016/0360-8352(96)00065-4

Lisnianski, Anatoly, Frenkel, Ilia, \& Ding, Yi. (2010). Multi-state System Reliability Analysis and Optimization for Engineers and Industrial Managers [electronic resource]: Dordrecht : Springer, 2010

Mamilla, Venkata Ramesh, \& Sekhar, Meda Chandra. (2010). Advanced Manufacturing \& Nanotechnology. International Journal of Nanotechnology \& Applications, 4(2), 67-71

Martin-Vega, Louis. (2008). Leading the way. Industrial Engineer: IE, 40(12), 38

Mummolo, G. (2007). The future for industrial engineers: education and research opportunities. European Journal of Engineering Education, 32(5), 587-598. doi: 10.1080/03043790701433350

Noble, D. (1999). The Religion of Technology. New York: Penguin Books 
OOH. (2013). Industrial Engineers. from http://www.bls.gov/ooh/architecture-andengineering/industrial-engineers.htm

Pool, R. (2012). Smart Living: Smart materials. Engineering \& Technology (17509637), 7(6), 31-36. doi: 10.1049/et.2012.0617

Ravesteijn, Wim, De Graaff, Erik, \& Kroesen, Otto. (2006). Engineering the future: the social necessity of communicative engineers. European Journal of Engineering Education, 31(1), 63-71. doi: 10.1080/03043790500429005

Saddik, Abdulmotaleb, Yang, Dongsheng, \& Georganas, Nicolas. (2007). Tools for transparent synchronous collaborative environments. Multimedia Tools and Applications, 33(2), 217-240

Sánchez-Hermosilla, Julián, González, Ramón, Rodríguez, Francisco, \& Donaire, Julián G. (2013). Mechatronic Description of a Laser Autoguided Vehicle for Greenhouse Operations. Sensors (14248220), 13(1), 769-784. doi: 10.3390/s130100769

Schöner, H. P. (2013). Automotive mechatronics. Control Engineering Practice, 12, 13431351. doi: 10.1016/j.conengprac.2003.10.004

Shibata, Hiromichi. (2009). A comparison of the roles and responsibilities of manufacturing engineers in Japan and the United States. International Journal of Human Resource Management, 20(9), 1896-1913. doi: 10.1080/09585190903142365

Shyr, Wen-Jye. (2012). Teaching mechatronics: An innovative group project-based approach. Computer Applications in Engineering Education, 20(1), 93-102. doi: $10.1002 /$ cae. 20377

Singh, Jasprit. (2005). Smart electronic materials : fundamentals and applications / Jasprit Singh: Cambridge : Cambridge University Press, 2005

Taisch, M., Cammarino, B. P., \& Cassina, J. (2011). Life cycle data management: first step towards a new product lifecycle management standard. International Journal of Computer Integrated Manufacturing, 24(12), 1117-1135. doi: 10.1080/0951192X.2011.608719

Tarik Ozbolat, Ibrahimchen Howard. (2013). Manufacturing living things. Industrial Engineer: IE, 45(1), 30

Templin, Paul. (2013). Why am I an industrial engineer? Industrial Engineer: IE, 45(2), 2424

Torry-Smith, J. M., Qamar, A., Achiche, S., Wikander, J., Mortensen, N. H., \& During, C. (2013). Challenges in Designing Mechatronic Systems. Journal of Mechanical Design, 135(1)

van Amerongen, Job. (2013). Mechatronic design. Mechatronics, 13, 1045-1066. doi: $10.1016 /$ S0957-4158(03)00042-4

Willemze, F. G. (1982). The challenge of a changing society to Industrial Engineering. International Journal of Production Research, 20(3), 311

Wilson, D. I. (2013). Navigating the wilds of industrial optimisation. Australian Journal of Multi-Disciplinary Engineering, 9(2), 117-123. doi: 10.7158/N13-GC09.2013.9.2

Wong, M., Hafner, J., Whitmire, K., Colvin, V., \& Tomson, M. (2007). Nanomanufacturing: Designing, Improving and Producing Nanoparticles

Yu, Wang, Ying, Yu, Chun, Xie, Xiaoyang, Zhang, \& Weizhi, Jiang. A proposed approach to mechatronics design education: Integrating design methodology, simulation with projects. Mechatronics. doi: 10.1016/j.mechatronics.2012.10.02

Zascerinska, Jelena. (2010). Communicative Competence: Existing Concepts and Prospects for Further Development: Online Submission

Zhong, J. L. (2012). Smart materials and nanotechnology in engineering [electronic resource]: selected, peer reviewed papers from the 2011 International Conference on Smart Materials and Nanotechnology in Engineering (SMNE 2011), September 17-18, 2011, Wuhan, China / edited by J.L. Zhong: Durnten-Zurich : Trans Tech Publications, 2012 